Article title: Covid-19 as an Accelerator for Training and Technology Adoption by Academics in Large-Scale Open and Distance Learning Institutions in Africa

Authors: Mphoentle Puleng Modise[1], Geesje Van den Berg[2]

Affiliations: Department of Curriculum and Instructional Studies, CEDU, University of South Africa[1]

Orcid ids: 0000-0002-2817-6329[1], 0000-0002-0306-4427[2]

Contact e-mail: modismp@unisa.ac.za

License information: This work has been published open access under Creative Commons Attribution License http://creativecommons.org/licenses/by/4.0/, which permits unrestricted use, distribution, and reproduction in any medium, provided the original work is properly cited. Conditions, terms of use and publishing policy can be found at https://www.scienceopen.com/.

Preprint statement: This article is a preprint and has not been peer-reviewed, under consideration and submitted to UnisaRxiv for open peer review.

DOI: 10.25159/UnisaRxiv/000016.v1

Preprint first posted online: 27 May 2021

Keywords: academic professional development, training, digital skills, Covid-19, e-learning, ODL, technology adoption, technology acceptance 


\section{Covid-19 as an Accelerator for Training and Technology Adoption by Academics in Large-Scale Open and Distance Learning Institutions in Africa}

\section{Mpho-Entle Puleng Modise}

https://orcid.org/0000-0002-2817-6329

University of South Africa

modismp@unisa.ac.za

\author{
Geesje Van den Berg \\ https://orcid.org/0000-0002-0306-4427 \\ University of South Africa \\ Vdberg@unisa.ac.za
}

\section{Abstract}

The Covid-19 pandemic provoked a paradigm shift never imagined by higher education institutions in the world, but especially in developing countries. Drawing on findings from a $\mathrm{PhD}$ study, this article aims to highlight the way in which Covid-19 accelerated professional development and training and technology adoption by academics in higher education institutions and largescale open and distance learning institutions in Africa. A total of 20 academics and relevant stakeholders from two of Africa's largest open and distance learning institutions were interviewed, and their views are reported. The data were analysed using thematic analysis. The findings show an increase in training and professional development of academics during the pandemic. The study also reveals the way in which Covid-19 fostered the speed and ease with which technology was adopted and used by academics for teaching and learning. The results of this research study may contribute to research of various topics on technology adoption and academics' professional development and training and future approaches post-Covid-19.

Keywords: academic professional development, training, digital skills, Covid-19, elearning, ODL, technology adoption, technology acceptance

\section{Introduction and Background}

Academic professional development (APD) and technology adoption have been some of the most researched topics in higher education (HE) and distance education (DE). The everchanging technological developments and innovations, such as e-learning and the Fourth Industrial Revolution (4IR) (Mhlanga and Moloi 2020), within the teaching and learning spaces require that both learners and instructors continuously equip themselves with relevant digital skills and knowledge.

E-learning has brought about an unprecedented and disruptive revolution in HE (Garrison, Anderson, and Archer 2003), with the promise to widen access to quality HE. In order to redress the educational imperatives such as improving the capacity of the education and training systems to meet the pressing needs in Africa and other 
developing economies, countries such as South Africa, Nigeria, Botswana, Kenya, Namibia and Tanzania have embarked on digital transformation policies and educational innovations such as e-learning. The United Nations Educational, Scientific and Cultural Organization's (UNESCO) Millennium Development Goals for education for all for the twenty-first century of expanding access to education (Pandor 2009) have driven the adoption and use of information communications technologies (ICTs) in education to implement and fast-track the much-needed radical transformation of the education systems in Africa.

Most higher education institutions (HEIs) in Africa have started embarking on elearning and blended learning approaches; however, much-needed training of the lecturers to be equipped and prepared to teach using new systems and tools of education delivery has been a major challenge. Technology adoption has also been negatively impacted by resistance to change by faculty (Masalela 2011), limited financial resources for training (Mtebe and Raphael 2013), the lack of incentives, and the fact that faculty is "severely uninformed about e-learning in general" (Price et al. 2011, vii).

The Covid-19 pandemic and subsequent lockdowns revealed that many HEIs and lecturers were not fully prepared for the sudden move from face-to-face or blended approaches to full online education (Dwivedi et al. 2020). The Covid-19 pandemic has affected all aspects of life, from business, education, to social activities, shifting the paradigm and accelerating lecturers' training and technology adoption, all dependent on technology (Manzanedo and Manning 2020). This include HEIs needing to continue providing educational services by migrating to digital environments (Deslandes and Coutinho 2020). Technology, which has been central to teaching and learning in DE for decades (Aoki 2012), has once again proven to be the most effective vehicle through which education can be disseminated.

This research focused on the University of South Africa (Unisa) and the National Open University of Nigeria (NOUN), and reports on the way in which Covid-19 accelerated the training, adoption and use of technology for teaching and learning of their academics. The question guiding the study is: "How did the Covid-19 pandemic impact on training and technology adoption of academics in large-scale open and distance learning institutions in Africa?"

\section{Literature Review}

$\mathrm{DE}$ is framed within larger socio-economic and political contexts both in developing and developed countries. Evans and Haughey (2014) believe that DE is susceptible to the sequence of global crises, such as the emergence of the Covid-19 pandemic which broke out in late 2019 (Chan et al. 2020) and led to world lockdown early in 2020. Institutions worldwide suspended contact teaching with the provision of online DE being the only solution, highlighting the urgent need for digital competencies in HE and DE. 
Digitisation of education in Africa has not only been happening among DE institutions, but also among other traditional HEIs, which have gradually been operating in blended learning modes (Gachago et al. 2007). However, the pandemic has forced many educational institutions that would have otherwise not embarked on digital educational technologies to implement DE and e-learning strategies (Sahu 2020; Schleicher 2020). As a consequence, the eminent requirement for the training of educators in the use of digital technologies became necessary.

Digital literacy is believed to be key in digitalised education systems (Falloon 2020). At the centre of any successful learning activity is well-trained and adequately supported academic teaching staff. Ferrari, Punie and Redecker $(2012,79)$ believe that digital competence is a "multi-faceted moving target" that constantly evolves as new technologies appear, and thus training and development of academics need to be strategically placed within this uncertainty. Although all educational services had to take place digitally overnight, Dwivedi et al. (2020) argue that the key lessons of the pandemic for decision makers are to ensure that they have the ability to harness the power of technology to learn and to be better prepared for future waves and viruses.

\section{Theoretical Framework}

Technology adoption and acceptance gained popularity over the last decades (Gunasinghe et al. 2019), and thus attracted a flood of models and theories. The unified theory of acceptance and use of technology (UTAUT) which was chosen as the theoretical framework for this study, is one of the products and a response to the influx of technology acceptance models (TAMs).

The UTAUT is a combination of a spectrum of theories that have been used and empirically tested in various diverse contexts to understand and predict behaviour in respect to technology adoption and use. It was developed by Venkatesh et al. (2003) and comprises four key elements, namely, performance expectancy (individuals believe the system helps attain the desired job performance), effort expectancy (degree of ease associated with the use of the system), social influence (an individual's perception of the importance others have in the new system) and facilitating conditions (an individual belief that there is enough support in place to use the new system). There are four moderating variables, namely, age, gender, experience, and voluntariness of use (Venkatesh et al. 2003).

When an institution decides to adopt and implement new technology to ultimately improve processes and performance, one assumes that management will ensure that the facilitating conditions are conducive to such an innovation to be easily accepted by the ultimate users, especially the lecturers and students in HE and DE environments. The voluntariness of use in the context of HEIs is important because of its ability to facilitate and accelerate the intentionality and effort needed by lecturers to voluntarily learn how to use new and emerging technologies to teach and support students. Research supports 
the notion of staff development as an important consideration when implementing any innovation, including the implementation of technology initiatives such as e-learning (Cresswell, Bates, and Sheikh 2013; Ncube, Dube, and Ngulube 2014).

The facilitating conditions and behavioural intention that were identified in UTAUT are seen by Venkatesh et al. (2003) as determinant factors of actual use. Afonso et al. (2012) also found that moderating factors played an important role in the users' use of technology. With the recent debate on gender participation in HEI, it is also important to see what role gender plays in the use of technology for teaching and learning in open and distance higher education.

\section{Methodology}

For this study, a qualitative multiple case study design was used to guide the data collection and analysis. The use of this case study design was grounded within the interpretivist epistemology to understand the perceptions of the academic and nonacademic staff members regarding the training and adoption of e-learning technologies (Maree 2010), in large-scale HEIs in DE. The interpretivist paradigm was deemed suitable for qualitative research and data collection methods such as the interviews used in this study (Creswell and Creswell 2017).

\section{Sampling}

Purposive sampling was relevant for this study because of its flexibility in allowing researchers to invite candidates "according to their availability and accessibility" (Elfil and Negida 2017, 2), and its unique characteristics relevant for this study. Snowballing was also used to refine and further identify more relevant participants (Cohen, Manion, and Morrison 2011), especially with the participants from Nigeria, where there was no direct access to the population (Elfil and Negida 2017). The aim was to target candidates with relevant knowledge and experience on the topic of APD, e-learning implementation, readiness and technology adoption in HE and open and distance learning (ODL) environments. A sample of 20 participants from the two universities was chosen; eight from NOUN and twelve from Unisa.

\section{Data Collection}

Data were collected using semi-structured interviews, because these interviews allowed unrestricted exploration of issues under investigation and an opportunity for follow-up questions (Iyamu 2018). Owing to the pandemic regulations, the interviews were conducted and recorded online via Microsoft Teams and Zoom. The interviews conducted on Microsoft Teams were recorded in video file format, and these were converted to audio files to protect the identity of the participants, whereas the Zoom video recordings were automatically converted into audio files. The interviews were transcribed by a professional transcriber and verified by the researchers. Although the interview questions were informed by literature and the research questions, this study 
also involved a pilot study to further test the quality and viability of the interview schedule (Morin 2013). The questions were adjusted based on the feedback.

\section{Data Analysis}

Thematic analysis, which helps with identifying patterns (themes) within data (Braun and Clark 2019) and making sense of them, was conducted to answer the research question, (Tarsila et al. 2014) using Atlas.ti software. Deductive coding (with a pre-set coding schemes derived from interview questions and preliminary scanned text) and inductive coding (codes derived from the data) (Azungah 2018) were used in the analysis to reap the maximum benefits of both approaches and also to balance the limitations that each approach presents (Ligurgo et al. 2017).

\section{Trustworthiness}

Trustworthiness in qualitative research refers to "quality, authenticity, and truthfulness of findings of qualitative research, and it relates to the degree of trust, or confidence, readers have in results" (Schmidt and Brown 2015, 548). Trustworthiness is measured through credibility, dependability, confirmability and transferability (Amankwaa 2016; Lincoln and Guba 1985). Some of the strategies employed in qualitative research to ensure rigour and trustworthiness include "member checking, triangulation, detailed transcription, systematic plan and coding" (Gunawan 2015,11). The processes undertaken in this research are clearly and thoroughly documented, and relevant methods and tools were also explained in the preceding sections. The advantage of research digital tools is that a trail is automatically created, such as coding and data analysis with computer programs, and audios and videos are recorded; therefore, one can show proof of accounts. All recorded interviews, email invitations and communication with participants and other relevant stakeholders are securely kept by the researchers, and can be made available within reasonable ethical boundaries, should the request be made. This research is thus confirmable.

Transparency, which is one of the key ingredients of credibility (Yin 2011) was ensured by reiterative consultation process between the researchers. Transferability, which is the generalisability of research results (Houghton et al. 2013), was ensured by thoroughly describing critical processes and procedures that helped to construct, shape, connect and relate the meanings associated with the issues under investigation (Cohen, Manion, and Morrison 2011). Although pilot studies do not always guarantee the success of the main study (Van Teijlingen and Hundley 2010), they can strengthen the quality and rigour of a research project, if well executed and the feedback appropriately implemented. The feedback from the pilot study in this research was used to refine the research questions and sampling methods.

\section{Ethical Considerations}

Internet-mediated and online technologies have affected the way in which research is done. Steffen (2016) and Webster, Lewis and Brown (2013) mention the necessity of 
issues such as gaining consent from the participants when conducting research through online platforms. The ethical considerations such as confidentiality, anonymity and informed consent were observed throughout the research (McMillan and Schumacher 2010). Ethical clearance was granted by both universities, and then the participants were invited via email with all the relevant information about the research and informing them of their rights and the consent forms. The data were analysed truthfully without manipulating the participants' views and are presented in this report in a way that their comments cannot be traced to identify them (Steffen 2016).

The issue of gatekeepers in research remains relevant and is "an integral part of an ethical process of seeking authorisation for research" (Kay 2019, 37). Gatekeeping can be a big issue when research is done outside the researcher's organisation, country or any external setting that require involving gatekeepers or decision makers who hold the keys to certain elements of the research. Fortunately, there was no negative gatekeeping with the two universities in this study. Following purposive and snowballing techniques as already discussed, the participants from Nigeria were identified by the university's Directorate of Research Administration and Advancement, based on the specific inclusion and exclusion criteria provided by the researchers, and email invitations were sent to the identified participants. All the participants were informed of their rights, that their participation is voluntary, and that they were free to withdraw from the study at any time.

\section{Findings and Discussion}

This section presents the findings focusing on the trajectory of the Covid-19 through two major emerging themes with subthemes (Table 1). The 20 selected participants were between the ages of 35 and 67, of which 7 were males and 13 were females, and had between 3 and 40 years' experience in HE. The participants included academics, staff from the departments that play an important role in the continuous professional development of staff, staff from ICT departments, and staff from various levels of management of the universities.

The purpose of the study was not to compare findings, but to get a collective result of the Covid-19 pandemic impact on training and technology adoption of academics in large-scale ODL institutions in Africa. For this reason, the names and reference to the specific institutions have been removed, as indicated in Table 2 .

Table 1: Emerging themes from the study

\begin{tabular}{|l|l|}
\hline Emerging themes from the study \\
\hline Theme 1 & $\begin{array}{l}\text { Professional development and training of academics in } \\
\text { higher education and distance education }\end{array}$ \\
\hline Theme 2 & Technology adoption and use \\
\hline
\end{tabular}


Table 2: Participants $(n=20)$

\begin{tabular}{|l|l|}
\hline Types of participant & Symbol \\
\hline Academics & A1 to A13 \\
\hline Other participants & P14 to P20 \\
\hline
\end{tabular}

\section{Theme 1: Professional Development and Training of Academics in Higher Education and Distance Education}

The participants from both universities initially showed enthusiasm about the opportunities and future of e-learning in Africa, yet with a concern about the muchneeded training for teaching and learning, which was highlighted by the need to continue teaching using technology during the lockdown. Most participants believed the teaching staff from both universities were not equipped and well-prepared for e-learning in terms of digital skills.

It appeared that some academics in both universities did not know how to use their computers to find materials or files and were challenged in finding information. Backing up files was a major effort for some or navigating the universities' learning management system (LMS). One would assume that ODL lecturers should have been the most ready and capable of delivering education online, however, teaching and assessing in online environments were also found to be a major struggle for academics from both institutions. This led to an increase in requests from colleagues for training and refresher training on using the universities' LMS platforms, as indicated by one participant from the training and development unit in one of the universities:

During lockdown in March 2020, that's where we got so much training requests for Microsoft teams. Microsoft Teams at [university name] was introduced in 2018, we used to train two, three, less than 10 people, but came March 2020 during lock down, we were overwhelmed with training requests, especially academics. (P18)

Most lecturers believed that working online or using the universities' LMS was timeconsuming, hence the LMS was not regularly used. It also appears that both institutions do not have e-learning policies that regulated and/or enforced transition to LMS teaching pre-pandemic. Nevertheless, the pandemic forced many to interact with online teaching tools, including administering examinations online. One of the major challenges identified during the Covid-19 pandemic for one university was migrating all examinations online, as indicated by this participant:

... from an assessment point of view, we are still struggling with a lack of knowledge of the available tools in administering the exam, due to Covid-19; we had to interact with those tools in ensuring that we deliver online exams ... the administration of the online examination was difficult for some to adapt to that change, so there's a need for adequate training. (A4) 
However, a participant from another university reported that the online examinations was not a problem for them because they have been doing online exams before the Covid-19:

And when this issue of Covid-19 started, it was very easy for [university name] to go online and migrate, easy, no stoppage in the calendar, no stoppage in the institution ... and the learning. (A6)

The pandemic exposed everyone who did not previously try to refine or to develop skills and knowledge in using technology to perform their duties. This was highlighted by one of the participants who pointed out that

there are a lot of professors who do not know how to share the screen and do a presentation [on Microsoft Teams]. (P16)

The overwhelming increase in training requests was not only directed to those responsible for providing training and development services, but also to the ICT departments that were inundated with requests for basic functions that people should have ideally mastered to do by themselves, especially in ODL institutions, as indicated by one participant:

That's when you hear people needing constant support of ICT for the things which really do not need ICT, such as 'my computer is not working'. Not necessarily that their computers are not working, it's just that they don't know where [or how] to find their information. (A3)

Changing computer passwords, backing up files and using the university's soft phones via Microsoft Teams during the pandemic were some of the things that many could not do, as mentioned by two participants. The lack of commitment and compulsory training policies were mentioned by some participants, pointing out the fact that although the university provided training for basic computer skills and skills to use available tools provided by the institution, many of these training sessions were ignored by lecturers. Two participants stated:

Workshops took place and training opportunities were provided, but they were not compulsory. If training is not compulsory, then how do we as an institution make sure that people are prepared [for e-leaning]? (A1)

The university's LMS has always been here, but it wasn't compulsory for lecturers to use it, therefore the training to use it was also not compulsory for lecturers. (P19)

Heavy workloads and the lack of time are often given as the reasons by academics for not being able to attend training (Mokhtar et al. 2019). A participant said:

The first reason is there is just too much work in our department at the moment. We are six academics and we have got nineteen modules. (A2) 
However, some authors argue that unless training programmes are mandatory (and aligned with key performance areas), their attendance will remain skeleton (see Ödalen et al. 2019; Trowler and Bamber 2005). This aspect was echoed by the participants, as one stated:

Well, there needs to be compulsory training, in providing support to lecturers, the issue is there are these many nice workshops from CPD, but they struggle with attendance to those workshops, but [name of institution] need to start doing what Google and Microsoft have started, providing certificates for basic online skills that the lecturers have acquired. (A4)

However, the Covid-19 pandemic seems to have changed the perceptions towards training and the necessity to use the university LMS and other teaching and support tools. The issue of "retraining" and compulsory training were echoed by the participants from both institutions as a strategic support needed by lecturers with regular and training vital for teaching staff. One participant stated:

... regular orientation and capacity building programs, training and retraining of skills, as you know almost every day you have new ways of doing things and technology trends are changing. (A8)

Professional technology development seems to have been positively impacted and accelerated by the emergence of the pandemic. In this regard, Zawacki-Richter $(2020,218)$ reported that the pressure of the Covid-19 crisis "will have a positive effect on digital innovations in university teaching". The participants who are involved in the training and development departments at both institutions reported an overwhelming increase in training requests by lecturers for online teaching and learning:

We were overwhelmed with training requests ... people are supposed to use the tools that the university provide, especially academics, but clearly most were not using them. (P18)

... the big thing right now is that many of the academics, since the Covid-19 pandemic, have resorted to using Microsoft Teams, where before people never bothered with Teams. (P20)

From the findings it became clear that academics were unable to transfer knowledge to students without proper digital skills., as Modise $(2020,49)$ confirmed, "academics cannot impart and transfer to learners skills they themselves do not possess." However, those who were effectively using the universities' LMS and available tools pre-Covid19 became leaders in training and development:

We had champions and flowers that were flourishing that suddenly came out and helped through training, through mentoring and helping other colleagues how to do certain things. (P20) 
Whenever I got stuck, I called her and then I stopped doing it, because I felt guilty and I stopped. (A2)

This emergence of champions (academics who had experience in using technologies such as LMS to teach) during the pandemic proves that users' experience has an impact on effort expectancy of behavioural intention (Al-Qeisi, Dennis, and Abbad 2015). However, the challenge with champions is that they might eventually feel overstretched as training other lecturers does not form part of their tasks at the university. Although this form of skills transfer may be instant, effective and practical, if it is not creatively aligned with an incentive system, the "champions" may not feel inspired and motivated to continue with their services.

The reality that LMS, social media, online support for students, and the use of other digital media are essential motivated lecturers to seek relevant assistance and training. With all educational services migrating to online spaces during the lockdown, specific training on teaching in ODL spaces became a reality for all institutions, including the DE institutions (Deslandes and Coutinho 2020). One participant put it bluntly:

Covid-19 was a good accelerator and we are starting to see interest developing within colleges, where academics are upskilling themselves or trying different things that they wouldn't have tried to before. (A4)

The raised expectations by HEIs and students have motivated many lecturers to incorporate technology use in their teaching and consequently need relevant training.

\section{Theme 2: Technology Adoption and Use}

Dwivedi et al. (2020) point out that the pandemic has forced many organisations to undergo significant transformation in a short period, particularly impacting education, work and life. The Covid-19 pandemic and subsequent lockdowns forced many HEIs to migrate teaching and learning activities to online spaces, changed attitudes, and forced academics and learners to earnestly seek training and quickly adopt the necessary technology to teach and learn. Institutions learned during this pandemic that those who had some level of knowledge and skill in teaching with educational technology were much more prepared (Ferrel and Ryan 2020). However, the Covid-19 pandemic has generated the much-needed e-learning awareness for developing countries. The overnight move to online spaces facilitated the adoption and use of technologies for teaching and learning, as pointed out by one of the participants:

You have to engage people when introducing change, with this Covid-19, no one prepared anyone for the change. We were all forced to change, whereas before Covid19 , we needed to explain to academics why they needed to change to this new way of work. (P18)

One participant alluded to the complicated nature of e-learning innovations implementation processes, indicating that this may ideally be a five-to-ten-year project. 
However, institutions had to migrate teaching and learning activities online overnight. The pandemic acted as an accelerator and a motivator for many academics in distance learning institutions using e-leaning and blended systems. One participant remarked:

To digitise three-and-a-half thousand courses, put them all online in the learning management system ... You're not going to do that overnight. (P18)

Ferri, Grifoni and Tiziana (2020) argue that the pandemic acted as an accelerator and a motivator for many academics in distance learning institutions using e-leaning and blended systems. Many academics reportedly avoided using institutional technological teaching tools such as university LMS in the past. However, suddenly, the technological tools were needed as a vehicle to teach and support their students.

Interestingly, age was identified by a few participants as one of the major problems why academics were not adopting technology as they should. One participant stated:

... it is very difficult for people to try something new and to learn something new and then I think nowadays we are appointing more younger people in the college. But old people like me and some of my colleagues, you know it is hard to teach an old dog new ... tricks and I have heard already they are talking of our department as the SASSA department, because most of us are quite old [laugh]. (A2)

The South African Social Security Agency (SASSA) is an Agency that provides comprehensive social security services in South Africa (SASSA n.d.). One of the services is providing an older persons grant (pension) for persons not younger than 60 years, and so SASSA is symbolically used in this department for old age. In various contexts age has been attributed to influencing behavioural intention to adopt and use technology. Research investigating technology adoption among older adults has mostly focused on participants who are older than 46 years (Wang, Chen, and Chen 2017), although Zhao, Ni and Zhou (2018), and Berkowsky, Sharit and Czaja (2017) conducted studies on older persons over the age of 65 years. In various contexts, however, "older adults' willingness to adopt technology is associated with a variety of factors including the perceived value of the technology, confidence in learning the technology, and the perceived impact on quality of life" (Berkowsky, Sharit, and Czaja 2017, 1). Although purposive sampling was used, it is interesting to note that the youngest participant in this study was 35 years old and the overall average was 53 years. Two participants had this to say about age:

I think we underestimate the age factor because if you look at the age of some senior lecturers and professors in other colleges, they struggle to do the required technological jump. So, they still feel comfortable utilising paper-based material. (A4)

Our university's lecturers are very old. They're not that motivated to start something new. I think the younger generation is much more eager to start it, you know, and we can focus on them. (P19) 
Factors such as perceived usefulness, perceived ease of use, perceived impact on quality of life, perceived value of the technology, and the confidence in learning the technology have been attributed to having an impact on the final decision of older users whether to adopt technology or not. However, these decisions vary from context to context. There seems to be much hope from most participants in this study that the sudden change brought by the Covid-19 pandemic ignited an awakening to adopt and use technology for teaching duties. One participant stated:

People are getting there, they realise that they can't be techno-dinosaurs, and that they need to get up to speed. (P14)

Theories that explain the way in which technologies are accepted and adopted by academics in HE and DE abound. However, a different dimension emerged and caused a paradigm shift in the adoption and use of technology by academics. The urgent need to continue providing education became the determining factor for facilitating adoption and use of technology. Venkatesh et al. $(2003,467)$ identified variables from eight TAMs which were "confirmed as integral features of UTAUT" (age, gender, experience and voluntariness) as having a significant influence on technology adoption and behavioural intention. From this study, it seems as if age was an inhibitory factor for technology adoption at these institutions. Despite this factor, the urgency to continue teaching and learning, and to interact with others forced academics at HEIs to immediately adopt and use available technology.

Even though the lack of resources from the institutions was reported by the participants, many lecturers reported using their own resources to continue with their work and support students, which is in contrast to the UTAUT's facilitating conditions believed to predict technology use. Venkatesh et al. (2003) posited that voluntariness moderates the relationship between social influence and behavioural intention; however, Chiu and $\mathrm{Ku}$ (2015) argued that studies that are conducted in highly volunteer-driven environments have shown different relationships. Although only participants aged 34 upwards were available to participate in this study, as previously reported, lecturers, both male and female, of different age groups requested the training, while others were trying to work independently. Tan $(2013,4)$ defined voluntariness of use as the "degree to which use of the innovation is perceived as being voluntary or through one's free will". The situation thus did not give lecturers any option but to urgently and immediately learn to use available technology to teach and support students.

\section{Conclusion and Recommendations}

The study reported on the way in which the Covid-19 pandemic accelerated training and technology adoption by academics in two large-scale ODL universities in Africa. Lecturers were overwhelmed with tasks and responsibilities when forced to migrate all teaching, assessment, and student support activities to their universities' LMS, and reportedly requested training and support. Looking at the UTAUT's key elements and 
moderating variables, this study highlighted Covid-19 as one of the facilitating factors in adopting technology. The systematic approach that has always been recommended was overtaken by chaotic and spur-of-the-moment approaches that led to an increased adoption of technology, challenging theories of technology adoption and use as we know them. Both formal and informal approaches to training and development for digital skills were adopted, with the goal of gaining the relevant technological skills, evidenced by increased requests made to the training and ICT departments and the trend where colleagues were asking fellow colleagues for help with ICT-related issues.

This research therefore contributes to $\mathrm{HE}$ and DE knowledge and research, and the results will enrich future practices and research on academic technology adoption and APD. The main contribution of this paper is that, using the UTAUT which is a combination of eight tested TAMs, our empirical study identified age, voluntariness of use and gender as unimportant moderating factors for technology adoption by academics during the pandemic. The findings in this study suggest that pandemics can be major influential moderating factors in adoption of technology in $\mathrm{HE}$ and $\mathrm{DE}$ contexts.

The Covid-19 crisis might stimulate the design and development of new theories for future technology adoption and acceptance in $\mathrm{HE}$ and DE. We believe therefore that more research on future approaches to technology adoption of academics will be useful. Age-specific research may also bring insights on the way in which various age groups of academics within HE and DE adopt and use technology. Training of academics also needs to be timely, specific, relevant and appropriate for the technology being implemented. If not, it leaves lecturers confused and unable to use the tools to work, teach, learn and support their students. This is equally important for the institutions' internal training programmes, and thus this study recommends that the staff in training and development departments also receive continued training to keep themselves relevant and effective when supporting the ODL academics and to design training programmes based on the real needs of the university's teaching staff. To avoid any resistance and misunderstanding that may lead to failure, any e-learning implementation project should begin with an awareness and education for all of the university's stakeholders, not just the academics.

There is a need for HEIs institutions to design evaluation and monitoring strategies to continuously audit and assess the digital skills of their teaching staff. Training and development for both lecturers and students need to be relevant and timely, and especially aligned with the ever-changing technology. The aim of this study was to investigate the way in which the Covid-19 pandemic and subsequent lockdown accelerated training and technology adoption by academics and to document lessons learned for others to learn from these experiences. The research may be limited to the two African large-scale ODL institutions. However, the researchers believe that the lessons may be relevant and applicable to HEIs in similar contexts. Covid-19 forced 
many HEIs to do things differently, however, there are opportunities and positives that other researchers and HEIs may gain from this research.

\section{Acknowledgements}

We are grateful for the financial support from the University of South Africa through its academic qualification improvement programme, and the UNESCO Chair of ODL at Unisa. We are also grateful to our colleagues in the Open Distance Learning Research Unit for providing valuable and constructive comments on our first draft, the editor, and the peer reviewers for their insightful and thoughtful comments.

\section{References}

Afonso, C. Miguel, José Luis Roldán Salgueiro, Manuel Jesús Sánchez Franco, and María de la O. González. 2012. "The Moderator Role of Gender in the Unified Theory of Acceptance and Use of Technology (UTAUT): A Study on Users of Electronic Document Management Systems."

Al-Qeisi, Kholoud, Charles Dennis, and Muneer Abbad. 2015. "How Viable is the UTAUT Model in a Non-Western Context?" International Business Research 8 (2): 204-19. https://doi.org/10.5539/ibr.v8n2p204.

Amankwaa, L. 2016. “Creating Protocols for Trustworthiness in Qualitative Research” Journal of Cultural Diversity 23 (3).

Aoki, Kumiko. 2012. "Generations of Distance Education: Technologies, Pedagogies, and Organizations." Procedia - Social and Behavioral Sciences 55: 1183-7. https://doi.org/10.1016/j.sbspro.2012.09.613.

Azungah, Theophilus. 2018. "Qualitative Research: Deductive and Inductive Approaches to Data Analysis.” Qualitative Research Journal. https://doi.org/10.1108/QRJ-D-18-00035.

Berkowsky, Ronald W., Joseph Sharit, and Sara J. Czaja. 2017. "Factors Predicting Decisions about Technology Adoption among Older Adults." Innovation in Aging 1 (3): igy002. https://doi.org/10.1093/geroni/igy002.

Braun, Virginia, and Victoria Clarke. 2019. "Reflecting on Reflexive Thematic Analysis." Qualitative Research in Sport, Exercise and Health 11 (4): 589-97. https://doi.org/10.1080/2159676X.2019.1628806.

Chan, Jasper Fuk-Woo, Kin-Hang Kok, Zheng Zhu, Hin Chu, Kelvin Kai-Wang To, Shuofeng Yuan, and Kwok-Yung Yuen. 2020. "Genomic Characterization of the 2019 Novel Human-Pathogenic Coronavirus Isolated from a Patient with Atypical Pneumonia after Visiting Wuhan.” Emerging Microbes and Infections 9 (1): 221-36. https://doi.org/10.1080/22221751.2020.1719902. 
Chiu, Teresa M. L., and Benny P. S Ku. 2015. "Moderating Effects of Voluntariness on the Actual Use of Electronic Health Records for Allied Health Professionals." JMIR Medical Informatics 3 (1): e7. https://doi.org/10.2196/medinform.2548.

Cohen, Louis, Lawrence Manion, and Keith Morrison. 2011. Planning Educational Research: Research Methods in Education. New York: Routledge.

Cresswell, Kathrin M., David W. Bates, and Aziz Sheikh. 2013. "Ten Key Considerations for the Successful Implementation and Adoption of Large-Scale Health Information Technology." Journal of the American Medical Informatics Association 20 (e1): e9-e13. https://doi.org/10.1136/amiajnl-2013-001684.

Creswell, John W., and J. David Creswell. 2017. Research Design: Qualitative, Quantitative, and Mixed Methods Approaches. Sage.

Deslandes, Suely Ferreira, and Tiago Coutinho. 2020. "The Intensive Use of the Internet by Children and Adolescents in the Context of COVID-19 and the Risks for Self-Inflicted Violence." Ciencia et saude coletiva 25: 2479-86. https://doi.org/10.1590/141381232020256.1.11472020.

Dwivedi, Yogesh K., D. Laurie Hughes, Crispin Coombs, Ioanna Constantiou, Yanqing Duan, John S. Edwards, Babita Gupta et al. 2020. "Impact of COVID-19 Pandemic on Information Management Research and Practice: Transforming Education, Work and Life.” International Journal of Information Management 55: 102211. https://doi.org/10.1016/j.ijinfomgt.2020.102211.

Elfil, Mohamed, and Ahmed Negida. 2017. "Sampling Methods in Clinical Research: An Educational Review.” Emergency 5 (1).

Evans, Terry D., and Margaret Haughey. 2014. "Online Distance Education Models and Research Implications.” Online Distance Education: Towards a Research Agenda 131-49.

Falloon, Garry. 2020. "From Digital Literacy to Digital Competence: The Teacher Digital Competency (TDC) Framework." Educational Technology Research and Development 68 (5): 2449-72. https://doi.org/10.1007/s11423-020-09767-4.

Ferrari, Anusca, Yves Punie, and Christine Redecker. 2012. "Understanding Digital Competence in the 21st Century: An Analysis of Current Frameworks." In European Conference on Technology Enhanced Learning, 79-92. Berlin: Springer. https://doi.org/10.1007/978-3-642-33263-0_7.

Ferrel, Meganne N., and John J. Ryan. 2020. "The Impact of COVID-19 on Medical Education." Cureus 12 (3). https://doi.org/10.7759/cureus.7492.

Ferri, Fernando, Patrizia Grifoni, and Guzzo Tiziana. 2020. “Online Learning and Emergency Remote Teaching: Opportunities and Challenges in Emergency Situations." Societies 10 (4): 86. https://doi.org/10.3390/soc10040086. 
Houghton, Catherine, Dympna Casey, David Shaw, and Kathy Murphy. 2013. "Rigour in Qualitative Case-Study Research.” Nurse Researcher 20 (4). https://doi.org/10.7748/nr2013.03.20.4.12.e326.

Gachago, Daniela, Spoon Mafote, Anne Munene-Kabanya, and Marilyn Lee. 2007.

"Assessment of the Effectiveness of the CAD ELearning Certificate at the University of Botswana." International Journal of Education and Development Using ICT 3 (4): 71-88.

Garrison, D. Randy, Terry Anderson, and Walter Archer. 2003. "A Theory of Critical Inquiry in Online Distance Education.” In Handbook of Distance Education, edited by M. Moore and G. Anderson, 113-27. New York: Erlbaum. http://hdl.handle.net/2149/764.

Gunasinghe, Asanka, Junainah Abd Hamid, Ali Khatibi, and S. M. Ferdous Azam. 2019. "Academicians' Acceptance of Online Learning Environments: A Review of Information System Theories and Models." Global Journal of Computer Science and Technology. https://doi.org/10.34257/GJCSTHVOL19IS1PG31.

Gunawan, Joko. 2015. "Ensuring Trustworthiness in Qualitative Research.” Belitung Nursing Journal 1 (1): 10-11. https://doi.org/10.33546/bnj.4.

Iyamu, Tiko. 2018. “Collecting Qualitative Data for Information Systems Studies: The Reality in Practice." Education and Information Technologies 23 (5): 2249-64. https://doi.org/10.1007/s10639-018-9718-2.

Kay, Lynda. 2019. "Guardians of Research: Negotiating the Strata of Gatekeepers in Research with Vulnerable Participants." Practice 1 (1): 37-52. https://doi.org/10.1080/25783858.2019.1589988.

Ligurgo, Valèria, Thibault Philippette, Pierre Fastrez, Anne-Sophie Collard, and Jerry Jacques. 2017. “A Method Combining Deductive and Inductive Principles to Define Work-Related Digital Media Literacy Competences." In European Conference on Information Literacy 245-54. Cham: Springer. https://doi.org/10.1007/978-3-319-74334-9_26.

Lincoln, Yvonna S., and Egon G. Guba.1985. Naturalistic Inquiry. Beverly Hills: Sage. https://doi.org/10.1016/0147-1767(85)90062-8.

Manzanedo, Rubén D., and Peter Manning. 2020. "COVID-19: Lessons for the Climate Change Emergency." Science of the Total Environment 742: 140563. https://doi.org/10.1016/j.scitotenv.2020.140563.

Maree, David J. F. 2020. "The Methodological Division: Quantitative and Qualitative Methods.” In Realism and Psychological Science, 13-42. Cham: Springer. https://doi.org/10.1007/978-3-030-45143-1_2.

Masalela, Regina K. 2011. "Implementing E-Learning at the University of Botswana: The Practitioner's Perspective.” Online Journal of Distance Learning Administration 14 (2). 
McMillan, James H., and Sally Schumacher. 2010. "Research in Education: Evidence-Based Inquiry, MyEducationLab Series." Pearson.

Mhlanga, David, and Tankiso Moloi. 2020. "COVID-19 and the Digital Transformation of Education: What are We Learning on 4IR in South Africa?" Education Sciences 10 (7): 180. https://doi.org/10.3390/educsci10070180.

Modise, Mphoentle Puleng. 2020. "Continuous Professional Development and Student Support in an Open and Distance E-Learning Institution: A Case Study." International Journal of African Higher Education 7 (1). https://doi.org/10.6017/ijahe.v7i1.10902.

Mokhtar, Ikram Syah, Nor Hazana Abdullah, Bestoon Othman, Peshraw Mahmood Salman, and Darbaz Anwer Ismael. 2019. "Factor Comparison for Participation in Training Program: The View of Training Officer and Academic Staff at Public University Malaysia.” International Journal of Psychosocial Rehabilitation 23 (2): 1003-19. https://doi.org/10.37200/IJPR/V23I3/PR190346.

Morin, Karen H. 2013. "Value of a Pilot Study." Journal of Nursing Education 52 (10): 54748. https://doi.org/10.3928/01484834-20130920-10.

Mtebe, Joel, and Christina Raphael. 2013. "Students' Experiences and Challenges of Blended Learning at the University of Dar es Salaam, Tanzania." International Journal of Education and Development Using ICT 9 (3).

Ncube, Siphamandla, Luyanda Dube, and Patrick Ngulube. 2014. "E-Learning Readiness among Academic Staff in the Department of Information Science at the University of South Africa." Mediterranean Journal of Social Sciences 5 (16): 357. https://doi.org/10.5901/mjss.2014.v5n16p357.

Ödalen, Jörgen, Douglas Brommesson, Gissur Ó. Erlingsson, Johan Karlsson Schaffer, and Mattias Fogelgren. 2019. "Teaching University Teachers to Become Better Teachers: The Effects of Pedagogical Training Courses at Six Swedish Universities." Higher Education Research and Development 38 (2): 339-53.

https://doi.org/10.1080/07294360.2018.1512955.

Pandor, Naledi. 2009. "Achievements in Commonwealth Educational Co-Operation: Rising to 21st Century Challenges.” Round Table 98 (405): 679-85. https://doi.org/10.1080/00358530903371387.

Price, Ryan Michael, Kayla Mae Rayworth, Scott Stephen Brooks, and Taylor Bree Ketterer. 2011. "Enhancing E-Learning at the Polytechnic of Namibia."

Sahu, Pradeep. 2020. "Closure of Universities due to Coronavirus Disease 2019 (COVID-19): Impact on Education and Mental Health of Students and Academic Staff." Cureus 12 (4). https://doi.org/10.7759/cureus.7541. 
SASSA (South African Social Security Agency). n.d. "Old Age Grant.” Accessed 20 July 2021. https://www.sassa.gov.za/Documents/Grants-Documents/Older-PersonGrant.pdf.

Schleicher, Andreas. 2020. "The Impact of Covid-19 on Education Insights from Education at a Glance 2020." https://www.OECD.org/education/the-impact-of-covid-19-on-educationinsights-education-at-a-glance-2020.pdf.

Schmidt, N. A., and J. Brown. 2015. Evidence-Based Practice for Nurses: Appraisal and Application of Research. 3rd ed. Burlington: Jones and Bartlett Learning.

Steffen, Edith. 2016. "Ethical Considerations in Qualitative Research.” Analysing Qualitative Data in Psychology 2: 31-44.

Tan, Paul Juinn Bing. 2013. "Applying the UTAUT to Understand Factors Affecting the Use of English E-Learning Websites in Taiwan.” Sage Open 3 (4): 2158244013503837. https://doi.org/10.1177/2158244013503837.

Tarsila, M., G. Guest, K.M. MacQueen, and E. E. Namey. 2014. “Applied Thematic Analysis.” Canadian Journal of Program Evaluation 29 (1).

Trowler, Paul, and Roni Bamber. 2005. “Compulsory Higher Education Teacher Training: Joined-Up Policies, Institutional Architectures and Enhancement Cultures.” International Journal for Academic Development 10 (2): 79-93. https://doi.org/10.1080/13601440500281708.

Van Teijlingen, E., and V. Hundley. 2010. “The Importance of Pilot Studies.” Social Research Update 35 (4): 49-59.

Venkatesh, Viswanath, Michael G. Morris, Gordon B. Davis, and Fred D. Davis. 2003. "User Acceptance of Information Technology: Toward a Unified View." MIS Quarterly 425-78. https://doi.org/10.2307/30036540.

Wang, Kenneth Hsiche, Gong Chen, and Houn-Gee Chen. 2017. "A Model of Technology Adoption by Older Adults." Social Behavior and Personality: An International Journal 45 (4): 563-72. https://doi.org/10.2224/sbp.5778.

Webster, S., J. Lewis, and A. Brown. 2013. "Ethical Considerations in Qualitative Research.” Qualitative Research Practice: A Guide for Social Science Students and Researchers 77.

Yin, Robert K. 2011. Applications of Case Study Research. Thousand Oaks: Sage.

Zawacki-Richter, Olaf. 2020. "The Current State and Impact of Covid-19 on Digital Higher Education in Germany." Human Behavior and Emerging Technologies. https://doi.org/10.1002/hbe2.238. 
Zhao, Yang, Qi Ni, and Ruoxin Zhou. 2018. "What Factors Influence the Mobile Health Service Adoption? A Meta-Analysis and the Moderating Role of Age." International Journal of Information Management 43: 342-50.

https://doi.org/10.1016/j.ijinfomgt.2017.08.006. 